\title{
Simulation of concrete-frame collapse due to dynamic loading
}

Hakuno, M.

Toyo University, Department of Civil Engineering, Saitama, Japan

\begin{abstract}
The extended distinct-element method(EDEM) is used to construct models of multi-degrees-of-freedom systems for particles of concrete frames and to conduct a series of numerical simulations in which the particles collapsed due to seismic forces. When a concrete frame collapses, it is reduced to a pile of debris. If the debris is rejoined to form the concrete frame, the original shape is restored; i.e., the frame prior to collapse is considered to be an assembled body of concrete debris. The EDEM is a method for analyzing discontinuous bodies, but here we report on an analysis in which concrete debris is considered to contain the elements of a discontinuous body. For convenience, we assumed that the particle shape in the debris is circular and that the parts are connected by springs that satisfy the Mohr-Coulomb yield conditions. The results of the simulations are in good agreement with records of damage done by past earthquakes.
\end{abstract}

\section{INTRODUCTION}

Recent studies of the collapse of concrete structures have been based on fracture mechanics(Horii and Nemat-Nasser 1986; Fanella 1990) and plasticity(Chen 1982). The distinct-element method(DEM) proposed by Cundall(Cundall 1971; Cundall and Strack 1979), however, has been used to analyze the collapse of various structures composed of granular materials such as soil and rock. Examples include the fracture of a structural foundation(Uemura and Hakuno 1987), cliff collapse(Iwashita and Hakuno 1990), rock avalanches (Uchida and Hakuno 1990), debris flows(Hakuno and Uchida 1991) and liquefaction(Hakuno and Tarumi 1988). Iwashita and Hakuno(1990) proposed the extended distinct-element method(EDEM) as a modification of Cundall's distinct-element method by adding pore springs(Fig.1) to such pore material as clay between particles. More recently, the writers proposed that an aggregate of circular elements and mortar constituent pore springs would satisfy the conditions of fracture(Meguro and Hakuno 1989). Under these assumptions, we established a model for concrete by setting these pore springs among elements and then followed the fracture process(Meguro and Hakuno 1989). The EDEM, however, has a serious drawback in that it requires an enormous amount of calculation time because explicit numerical integration is unstable unless the time step used is very short. Therefore, should this EDEM method be applied to concrete structures, an analysis of the fracture of the whole structure would be prohibitive. Therefore, we analyze only the fracture of structural members composed of few elements. To simulate the fracture analysis of a whole structure, we reduced the number of elements as much as possible. For example, for a column, two circular elements are arranged through the member cross section because at least two elements are required to resist bending moment in the column. 
But, when the number of elements is drastically reduced, the model becomes oversimplified. The structure model may show a very different mode of fracture than that occurring when an actual structure fractures. I assume that a result that tells whether the structural component in question has broken down or has not broken down is satisfactory for purposes of studying fracture of the structure as a whole. Detailed information on the mode of local fracture of a particular part is sacrificed. When the number of elements is greatly reduced, the model resembles a multi-degree-of-freedom(MDOF) model common to earthquake-response analyses. The EDEM model proposed in the present study allows fracture separation to occur. Conditions in which elements become separated from one another after fracture are not allowed in analyses with MDOF models.

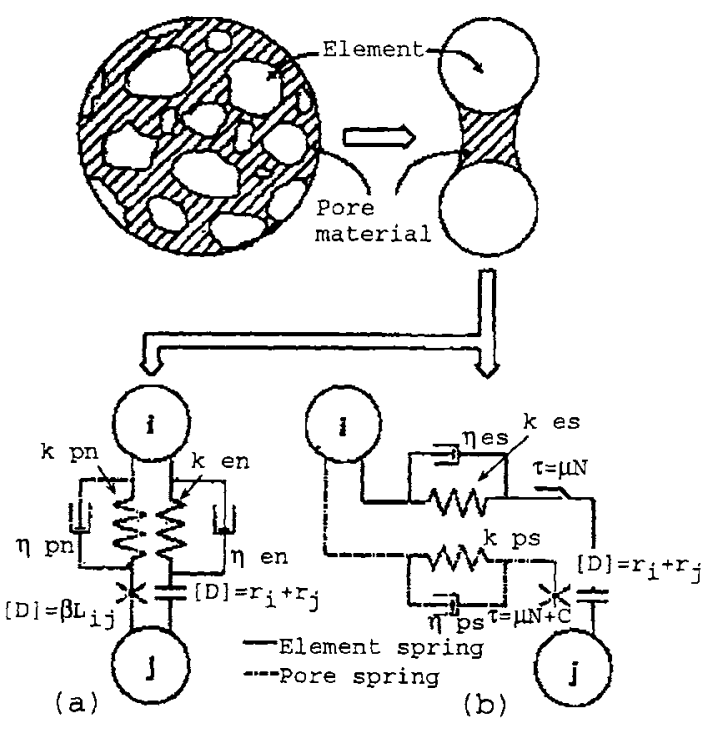

Fig. 1 EDEM modeling of concrete:(a) Normal direction;(b) Tangential direction

\section{EQUATION OF MOTION}

The motion of a particle element $i$ having mass $\mathbf{m}_{i}$ and moment of inertia $\mathbf{I}_{i}$ is

$$
\begin{aligned}
& \mathbf{m}_{i} \ddot{\mathbf{u}}+\mathbf{C}_{i} \dot{\mathbf{u}}+\mathbf{F}_{i}=0 \\
& \mathbf{I}_{i} \ddot{\phi}+\mathbf{D}_{i} \dot{\phi}+\mathbf{M}_{i}=0
\end{aligned}
$$

Fig. 2 EDEM simulation of bending test under vertical, constant-rate deformation(Mortar spring distribution)
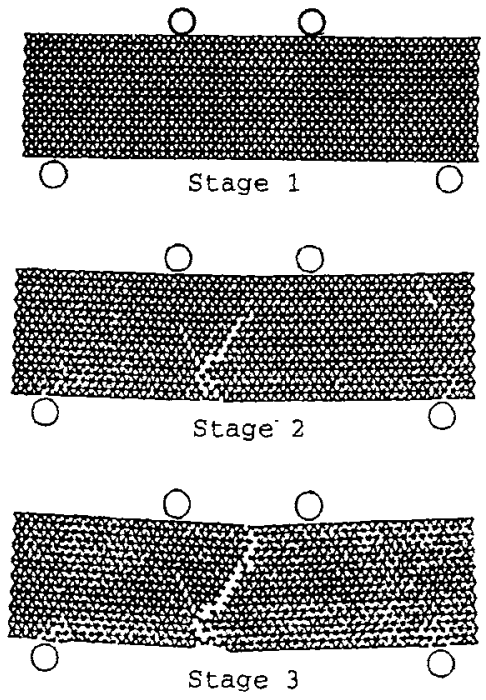
in which $\mathbf{F}_{i}=$ sum of all the forces acting on the particle; $\mathbf{M}_{i}=$ sum of all the moments acting on the particle; $\mathbf{C}_{i}$ and $\mathbf{D}_{i}=$ damping coefficients; $\mathrm{u}=$ displacement vector; and $\phi=$ angular displacement.

The dynamic response of the structure can be obtained in the time domain by step-bystep numerical integration of the equations of motion.

\section{SIMULATION RESULTS}

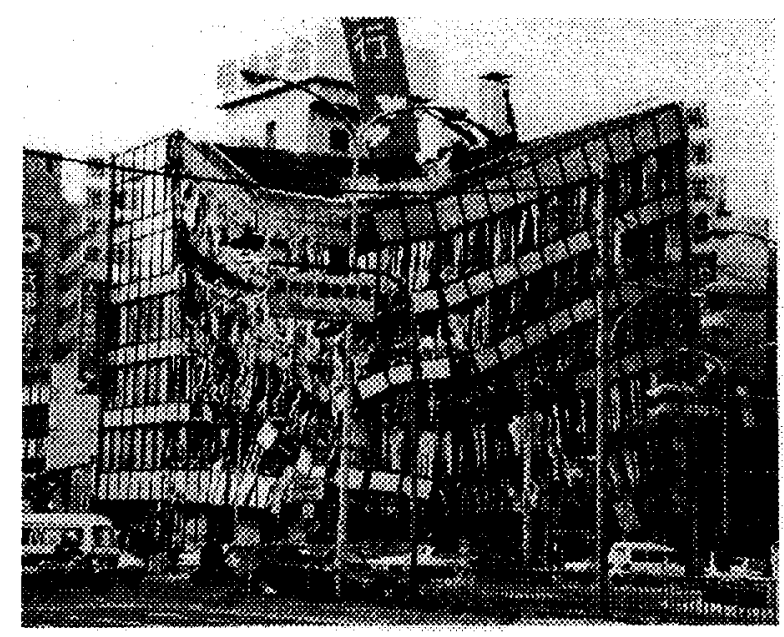

Fig. 3 Pancake-type collapse of building in Hanshin earthquake, Japan, 1995

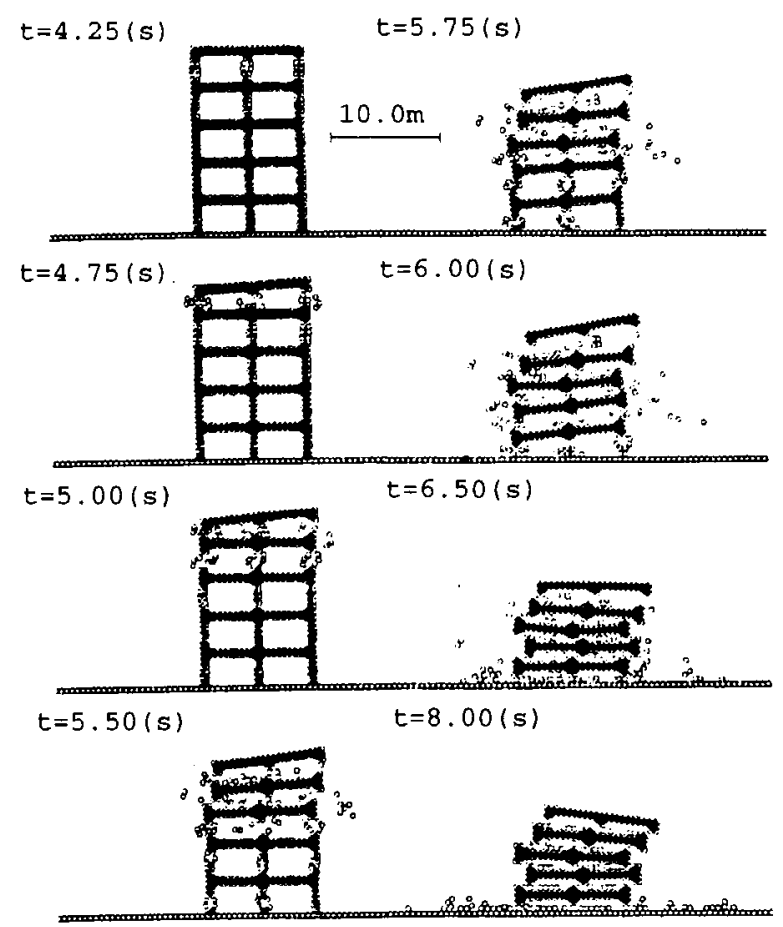

Fig. 4 Upper-story fracture and pancake collapse of five-story building because of horizontal seismic loading(Element and pore spring distribution) 


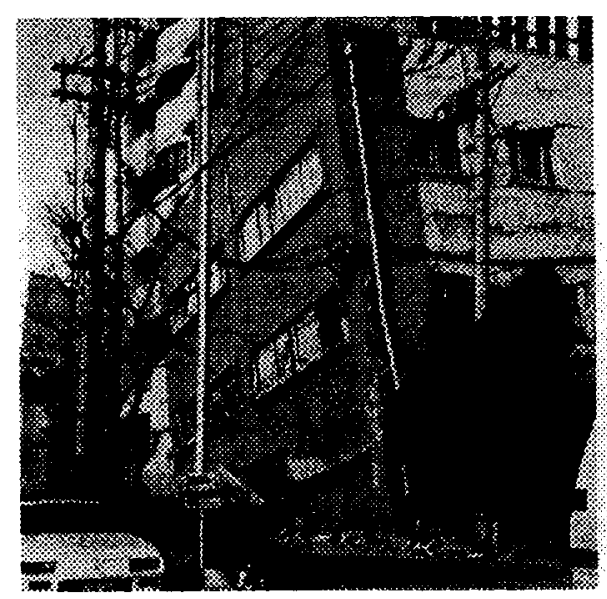

Fig. 5 Fracture only on first floor in Hanshin earthquake, Japan, 1995

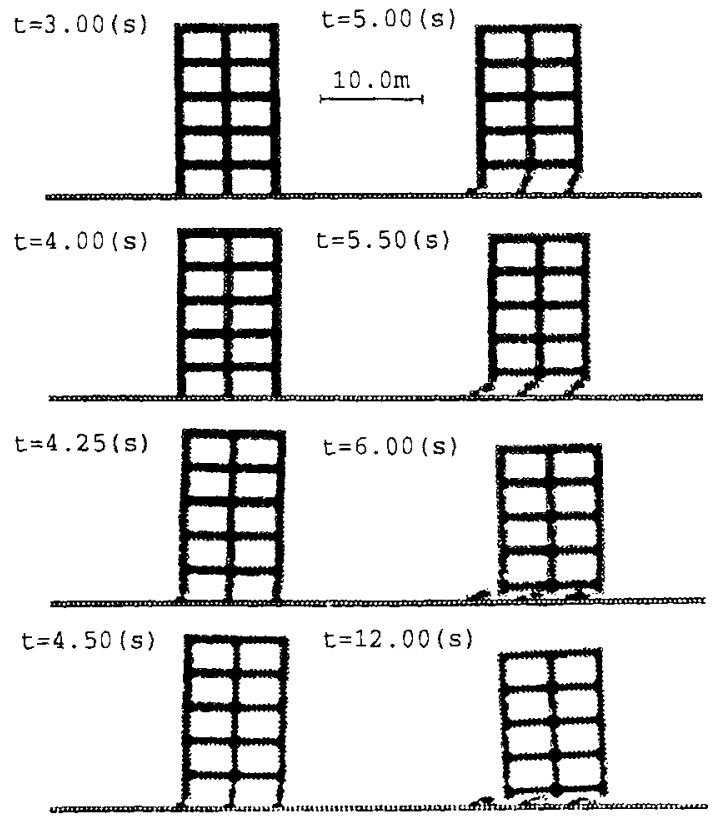

Fig. 6 Lower-story fracture of five-story building because of horizontal seismic loading (Element and pore spring distribution)

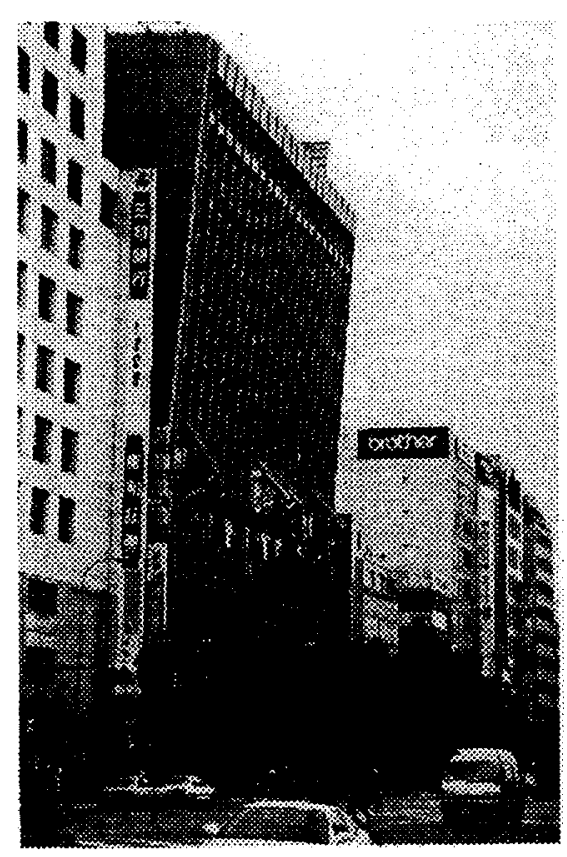

Fig. 7 Fracture only on intermediate floor in Hanshin earthquake, Japan, 1995

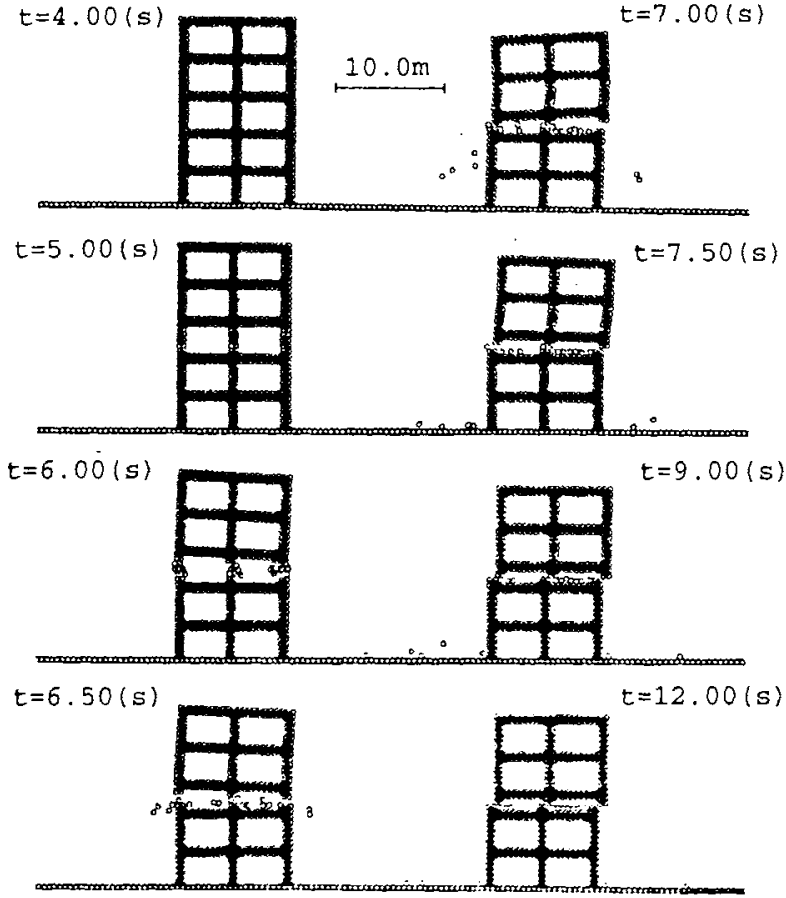

Fig. 8 Intermediate-story fracture of five-story building because of horizontal seismic loading (Element and pore spring distribution) 


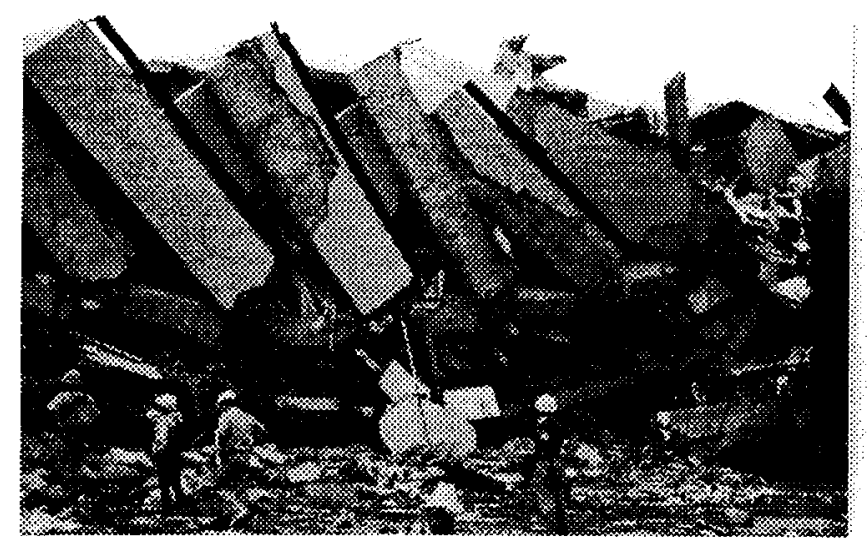

Fig. 9 Overturn type collapse in Philippines earthquake, 1990

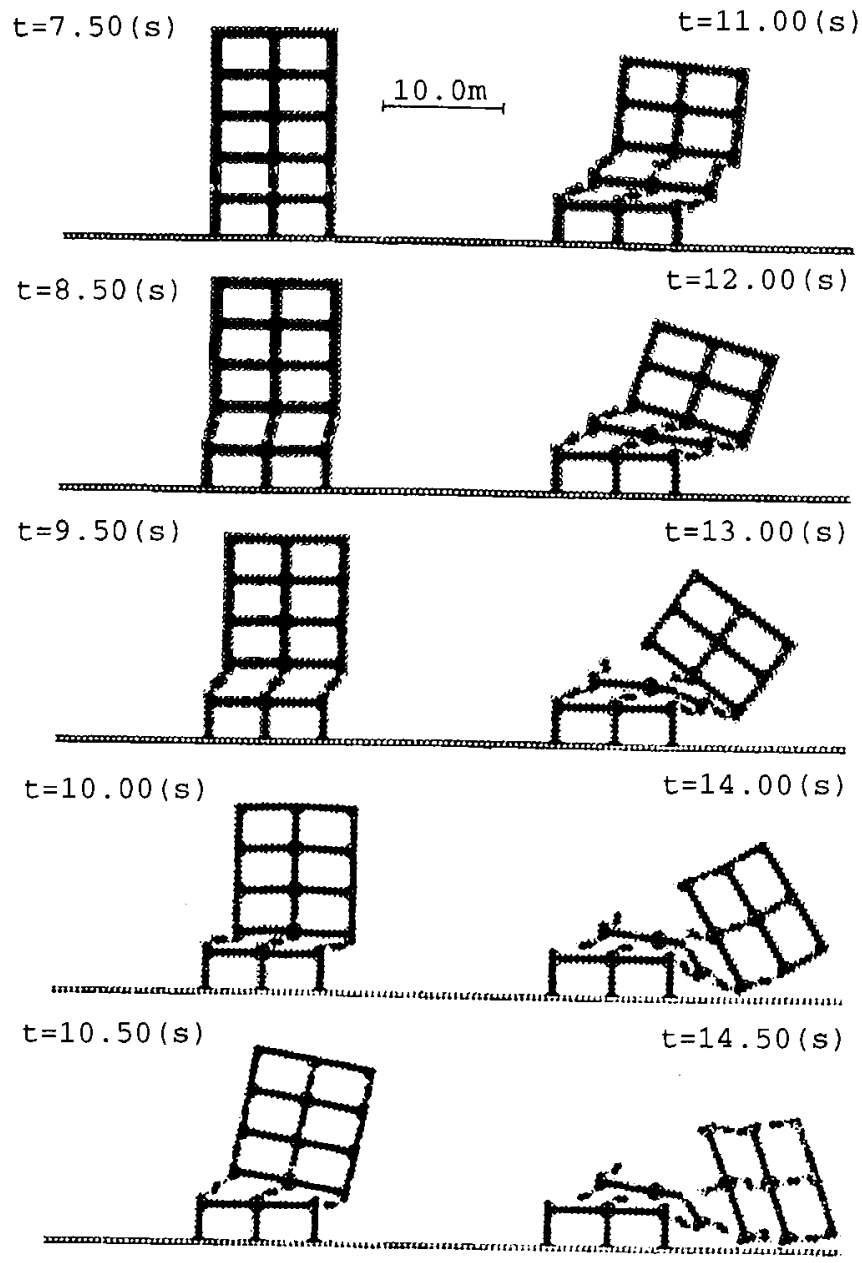

Fig. 10 Overturn type failure of five-story building because of horizontal seismic loading (Element and pore spring distribution) 


\section{REFERENCES}

Chen, W.F. 1982. Plasticity in reinforced concrete. McGraw-Hill, Inc., New York, N.Y. Cundall, P.A. 1971. A computer model for simulating progressive, large scale movement in blocky rock system. Symp., ISRM.Nancy, France, Proc.2, 129-136.

Cundall, P.A., and Strack, O.D.L. 1979. A discrete numerical model for granular assemblies. Geotechnique, London, England,2(1), 47-65.

Fanella, A.D. 1990. Fracture and failure of concrete in uniaxial and biaxial loading. J.Engrg. Mech.,ASCE,11(11),2341-2362.

Hakuno, M., and Tarumi, Y. 1988. A granular assembly simulation for seismic liquefaction of sand. Structural Engineering/Earthquake Engineering, Proc.JSCE, Japan Society of Civil Engineers, Tokyo, Japan, 5(2), 333s-342s.

Hakuno, M., and Uchida, Y. 1991. Application of the distinct element method to the numerical analysis of debris flows. Structural Engineering / Earthquake Engineering Proc. JSCE, Japan Society of Civil Engineers, Tokyo, Japan,5(2), 75s-85s.

Horii, H., and Nemat-Nasser, S. 1985. Compression induced microcrack growth in brittle solids: axial splitting and shear failure. J.Geophys.Res., 90(B4), 3105-3125.

Iwashita, K., and Hakuno, M. 1990. Modified distinct element method simulation of dynamic cliff collapse. Structural Engineering / Earthquake Engineering, Proc.JSCE, Japan Society of Civil Engineers, Tokyo, Japan, 7(1), 133s-142s.

Meguro, K., and Hakuno, M. 1989. Fracture analyses of concrete structures by the modified distinct element method. Structural Engineering/Earthquake Engineering, Proc.JSCE, Japan Society of Civil Engineers, Tokyo, Japan,6(2), 283s-294s.

Satake, M., and Jenkins, J.T.,eds. 1988. Micromechanics of granular materials. Proc. U.S./ Japan Seminar on the Micromech. of Granular Mat., Elsevier Scientific Publications, New York, N.Y.

Uchida, Y., and Hakuno, M. 1990. Distinct element analysis of dry rock avalanches. Structural Engineering/Earthquake Engineering, Proc.JSCE, Japan Society of Civil Engineers, Tokyo, Japan ,7(2), 206s-214s.

Uemura, D., and Hakuno, M. 1987. Granular assembly simulation with Cundall's model for the dynamic collapse of the structural foundation. Structural Engineering / Earthquake Engineering, Proc.JSCE, Japan Society of Civil Engineers, Tokyo, Japan, $4(1), 155 \mathrm{~s}-164 \mathrm{~s}$. 